\title{
Controle Químico da Queima de Folhas e da Mela de Estacas de Eucalipto, Causadas por Rhizoctonia spp.*
}

\author{
Silvaldo Felipe da Silveira1, Acelino Couto Alfenas², Luís Antônio Maffia ${ }^{2}$ \& Márcio Shiguero Suzuki \\ ${ }^{1}$ Laboratório de Proteção de Plantas, Centro de Ciências e Tecnologias Agropecuárias, Universidade Estadual do Norte \\ Fluminense, CEP 28015-620, Campos dos Goytacazes, RJ, fax: (022) 2726-1549, e-mail: silvaldo@uenf.br; ${ }^{2}$ Departamento de \\ Fitopatologia, Universidade Federal de Viçosa, CEP 36571-000, Viçosa, MG, fax: (031) 3899-2240
}

(Aceito para publicação em 08/08/2003)

Autor para correspondência: Silvaldo Felipe da Silveira

SILVEIRA, S.F., ALFENAS, A.C., MAFFIA, L.A. \& SUZUKI, M.S. Controle químico da mela de estacas e da queima de folhas de eucalipto, causadas por Rhizoctonia spp. Fitopatologia Brasileira 28:642-649. 2003.

\section{RESUMO}

Visando ao controle químico da queima de folhas e mela de estacas de eucalipto (Eucalyptus spp.) em viveiros florestais, avaliouse a eficiência de 12 fungicidas em inibir in vitro o crescimento micelial de um isolado epifítico de Rhizoctonia solani AG1-IB (RH-2). Sete fungicidas que inibiram totalmente o crescimento micelial do fungo, a concentrações inferiores a 100 ppm, foram pré-selecionados: methyltolclophos, benomyl, pencycuron, iprodione, thiabendazol, thiram e captan. Avaliou-se, ainda, a sensibilidade $\left(\mathrm{EC}_{50}=\right.$ dose provável que inibe o crescimento micelial em 50\%) aos fungicidas methyl-tolclophos, benomyl, iprodione e pencycuron de mais oito isolados patogênicos ao eucalipto, que diferem entre si quanto a virulência, morfologia, grupo de anastomose, número de núcleos por célula vegetativa e padrões eletroforéticos de proteínas e isoenzimas. Embora variações nos valores de $\mathrm{EC}_{50}$ entre algumas combinações de fungicidas e isolados tenham ocorrido, todos os isolados foram sensíveis aos quatro fungicidas testados $\left(\mathrm{EC}_{50} \leq 11 \mathrm{ppm}\right)$. Sob condições controladas, pulverizações com iprodione $(1,5 \mathrm{~g} / \mathrm{l})$, benomyl $(1 \mathrm{~g} / \mathrm{l})$, methyl-tolclophos $(1,5 \mathrm{~g} / \mathrm{l})$, thiram $(2,1 \mathrm{~g} / \mathrm{l})$, captan $(2 \mathrm{~g} / \mathrm{l})$ e pencycuron $(2 \mathrm{~g} / \mathrm{l})$ reduziram significativamente ( $\alpha=5 \%$ ) a incidência de folhas lesionadas por $R$. solani AG1, em brotações de mudas envasadas. Associadas à poda de limpeza, pulverizações de brotações de eucalipto em jardim clonal (no campo) com iprodione ( $1 \mathrm{~g} /$ 1) ou com mistura de benomyl $(0,5 \mathrm{~g} / \mathrm{l})+$ captan $(1 \mathrm{~g} / \mathrm{l})$, alternada com mistura de benomyl $(0,5 \mathrm{~g} / \mathrm{l})+$ thiram $(1 \mathrm{~g} / \mathrm{l})$, reduziram a incidência da mela de estacas na casa de vegetação $(\alpha=5 \%)$.

Palavras-chave adicionais: Eucalyptus sp., fungicidas, Rhizoctonia solani.

\section{ABSTRACT}

Chemical control of leaf scorch and web blight of eucalypt cuttings, caused by Rhizoctonia spp.

To achieve the chemical control of leaf scorch and web blight of eucalyptus (Eucalyptus spp.) cuttings in forest nurseries, 12 fungicides were assayed against one isolate of Rhizoctonia solani AG1-IB (RH-2). Seven fungicides (methyl-tolclophos, benomyl, pencycuron, iprodione, thiabendazol and captan) completely inhibited mycelial growth under concentrations lower than $100 \mathrm{ppm}$ of active ingredient on PDA culture. Additionally, the sensibility (EC50 = estimated dose for 50\% inhibition of mycelial growth) to methyltolclophos, benomyl, pencycuron and iprodione of another eight isolates differing in virulence, morphology, anastomosis groups, and proteins and isozyme profiles was evaluated. Little differences in sensitivity was observed in some combinations of fungicides-isolates. However, the eight isolates were sensitive to the four tested fungicides $\left(\mathrm{EC}_{50} \leq 11 \mathrm{ppm}\right)$. Under artificial conditions of inoculations, sprays of iprodione $(1,5 \mathrm{~g} / \mathrm{l})$, benomyl $(1 \mathrm{~g} / \mathrm{l})$, methyl-tolclophos $(1,5 \mathrm{~g} / \mathrm{l})$, thiram $(2,1 \mathrm{~g} / \mathrm{l})$, captan $(2 \mathrm{~g} / \mathrm{l})$, and pencycuron $(2 \mathrm{~g} / \mathrm{l})$ significantly $(\alpha=5 \%)$ reduced the incidence of leaf scorch on shoots of plants in vessels. Pruning of diseased shoots in clonal gardens (field) associated with weekly sprays of iprodione $(1 \mathrm{~g} / \mathrm{l})$ or mixtures of benomyl $(0,5$ $\mathrm{g} / \mathrm{l})+\operatorname{captan}(1 \mathrm{~g} / \mathrm{l})$ alternating with benomyl $(0,5 \mathrm{~g} / \mathrm{l})+$ thiram $(1 \mathrm{~g} / \mathrm{l})$, reduced the incidence of web blight on cuttings under shade house conditions $(\alpha=5 \%)$.

\section{INTRODUÇÃO}

No Brasil, algumas empresas florestais chegam a produzir mais de 100 mil mudas de eucalipto (Eucalyptus spp.) por dia, por meio de enraizamento de estacas ou miniestacas. Em áreas de viveiros destinadas à multiplicação de clones de eucalipto para a estaquia (jardins clonais e mini-jardins), o espaçamento reduzido, o intenso crescimento vegetativo das brotações após o corte das árvores e a irrigação por aspersão propiciam condições de ambiente favoráveis à incidência da

\footnotetext{
* Parte da Tese de Doutorado do primeiro autor. Universidade Federal de Viçosa (1996)
}

queima de folhas, causada por formas epifíticas de Rhizoctonia solani Kühn AG1 (Rezende \& Ferreira, 1992; Silveira et al., 2000). Quando brotações contaminadas são levadas ao galpão para a estaquia, perdas severas de mudas podem ocorrer durante o enraizamento, em virtude da mela de estacas. As condições de temperatura elevada e alta umidade da casa de vegetação, necessárias ao enraizamento, aliadas à debilidade fisiológica do material propagativo, favorecem a ocorrência da mela das estacas de eucalipto, causada por Rhizoctonia spp. Isolados não-epifíticos de Rhizoctonia spp. binucleada ou pertencentes a $R$. solani AG4, provenientes do solo ou substrato, causam igualmente a mela em estacas de eucalipto 
(Silveira et al., 2000).

As medidas recomendadas para o controle de podridões de estacas de eucalipto enquadram-se principalmente nos princípios de exclusão (uso de brotações sadias, substrato inócuo e lavagem de tubetes e bandejas); erradicação (remoção de estacas doentes e mortas do interior da casa de vegetação) e escape (canteiros suspensos e recipientes individuais para mudas e medidas que reduzem a possibilidade de inóculo permanecer e se disseminar no interior da casa de vegetação) (Ferreira, 1989).

O controle químico, por meio da imersão das estacas em calda fungicida ou por meio da pulverização das estacas plantadas, bem como o uso de desinfestantes para lavagem de tubetes e bandejas têm eficiência relativamente baixa contra inóculo de Rhizoctonia spp. (Ferreira et al., 1992; Silveira et al., 1992a; 1992b). Há a possibilidade de ocorrer efeitos fitotóxicos sobre o enraizamento e o desenvolvimento das mudas de eucalipto oriundas da estaquia (Silveira et al., 1993). O tempo de imersão em calda fungicida, necessário à desinfecção de estacas de eucalipto (Demuner et al., 1988; Ferreira et al., 1992; Silveira et al., 1992a; 1992b), é incompatível com a rotina de trabalho normalmente empregada no viveiro. Durante o período de enraizamento, o molhamento intermitente, via irrigação, impede a persistência de fungicidas na superfície das estacas (Ferreira et al., 1992), o que reduz a eficiência de controle e induz a pulverizações excessivas. $\mathrm{O}$ uso contínuo de fungicidas de grupos químicos com mesmo modo de ação sítio-específica, como benzimidazóis, em viveiros florestais, favorece o aparecimento de isolados de Cylindrocladium spp. resistentes a estes fungicidas (Alfenas et al., 1987).

Há carência de estudos específicos visando ao controle da queima de folhas causada por linhagens epifíticas de $R$. solani AG1 em jardim clonal de eucalipto. Espera-se que, associada à poda de limpeza e à coleta seletiva de brotos, a proteção com fungicidas possa inibir o crescimento micelial epifítico do patógeno sobre as brotações no jardim clonal e, conseqüentemente, reduzir a incidência da mela das estacas, dentro da casa de vegetação.

Segundo Kataria et al. (1991a), o sucesso do controle químico de rizoctonioses inespecíficas, causadas por diferentes espécies, grupos de anastomose e biótipos de Rhizoctonia, spp. requer que os fungicidas recomendados sejam eficientes contra os diferentes isolados do fungo. Rhizoctonia spp. são sensíveis a vários grupos de fungicidas, dentre os quais incluem-se os hidrocarbonetos aromáticos (PCNB, chloroneb e o fosforado methyl-tolclophos), benzimidazóis (benomyl, carbendazim, tiofanato-metílico e thiabendazol), carboximidas (carboxin), dicarboximidas (iprodione, vinclozolin e diclozolin), triazóis e triciclazóis (triadimenol, propiconazole, cyproconazole), morfolinas (fenpropimorph) e fenil-uréia (pencycuron). Todavia, existe variação quanto à sensibilidade aos fungicidas, avalidada pela inibição do crescimento micelial in vitro, entre várias espécies de Rhizoctonia (Kataria et al., 1991a) e entre diferentes grupos de anastomose de $R$. solani (Kataria et al., 1991b).

Visando ao controle químico da queima de folhas e da mela de estacas de eucalipto, causadas por Rhizoctonia spp., objetivou-se, neste trabalho, selecionar, in vitro, fungicidas inibidores do crescimento micelial de isolados de Rhizoctonia spp. Os fungicidas mais promissores quanto à inibição do crescimento micelial do fungo in vitro foram avaliados quanto à eficiência de controle das doenças, por meio de pulverizações de brotações de eucalipto inoculadas artificialmente, sob condições controladas de ambiente, e de brotações de eucalipto em jardim clonal, sob inoculação natural.

\section{MATERIALEMÉTODOS}

\section{Inibição in vitro do crescimento micelial de isolados de Rhizoctonia spp. por fungicidas}

Nos ensaios de laboratório, utilizaram-se oito isolados de $R$. solani patogênicos a estacas de eucalipto e distintos quanto a morfologia, grupo de anastomose de hifas, patogenicidade e padrões de proteínas e isoenzimas (Silveira et al., 2000; Silveira \& Alfenas, 2001). Num primeiro ensaio, avaliou-se a eficiência de 12 fungicidas em inibir in vitro o crescimento micelial do isolado RH-3, causador de queima de folhas em eucalipto (Silveira et al., 2000). Testaram-se: PCNB, captan, thiram, iprodione, methyl-tolclophos, clorotalonil, pencycuron, vinclozolin, carboxin, benomyl, thiabendazol e triadimenol; nas concentrações de 1, 10, 100 e 1.000 ppm (p/v) de ingrediente ativo (i.a.) em meio de BDA.

Num segundo ensaio, visando determinar possíveis diferenças de sensibilidade a fungicidas entre isolados de Rhizoctonia spp. patogênicos a estacas de eucalipto, avaliouse a eficiência de quatro fungicidas (methyl-tolclophos, benomyl, iprodione e pencycuron) em inibir in vitro o crescimento micelial dos oito isolados: RH-3 (R. solani AG1-IB similar), RH-15 (R. solani AG1-IC), RH-18 (R. solani AG1); RH6, RH-8 e RH11 ( $R$. solani AG4); RH-5 e RH-10 (isolados binucleados de Rhizoctonia sp.) (Silveira et al., 2000). Para isso, soluções-estoques (10.000 ppm de i.a. em acetona $10 \%$ em água destilada) de fungicidas foram diluídas em água esterilizada e acetona $10 \%$, conforme a concentração final desejada do princípio ativo fungicida em meio de cultura. Adicionaram-se $5 \mathrm{ml}$ da suspensão diluída de fungicida a $45 \mathrm{ml}$ de meio de BDA fundente $\left(50^{\circ} \mathrm{C}\right)$. Para se ter o equivalente em acetona, na testemunha (concentração 0 ), adicionou-se ao meio $5 \mathrm{ml}$ da solução de acetona $10 \%$. Após homogeneizada a mistura, verteram-se os $50 \mathrm{ml}$ de meio com fungicida em três placas de Petri ( $9 \mathrm{~cm}$ de diâmetro). Discos de culturas em BDA, de $7 \mathrm{~mm}$ de diâmetro, obtidos de extremidades de colônias com dois dias de idade, foram invertidos no centro das placas, sobre o meio sólido acrescido de fungicida. Incubou-se, sob escuro contínuo, a $25{ }^{\circ} \mathrm{C}$, e 36 a 40 h após, avaliou-se o crescimento micelial radial, medindo-se com régua graduada o diâmetro das colônias em dois sentidos ortogonais. Calculou-se a percentagem de inibição do crescimento micelial (PICM), pela fórmula: $\mathrm{PICM}=\left(\mathrm{D}_{\mathrm{t}}-\mathrm{D}_{\mathrm{n}}\right) \div\left(\mathrm{D}_{\mathrm{t}}-7\right) \times 100$; na qual $\mathrm{D}_{\mathrm{n}}=$ média das duas medições $(\mathrm{mm})$ de diâmetro das colônias do tratamento $\mathrm{n} ; \mathrm{D}_{\mathrm{t}}=$ média das duas medições $(\mathrm{mm})$ na testemunha (sem fungicida) 7 = diâmetro dos discos, em milímetro. Para cada 


\section{S.F. Silveira et al.}

combinação de fungicida-isolado, calculou-se o valor de $\mathrm{EC}_{50}$ (concentração inibitória do crescimento micelial em 50\%), por meio de regressão linear e transformação log-probit (programa SAEG - Sistema para Análises Estatísticas e Genéticas) (Euclides, 1983).

\section{Pulverização com fungicidas no controle da queima das folhas em brotações de mudas envasadas}

Para induzir brotações, deceparam-se plantas híbridas de Eucalyptus grandis Hill ex Maiden x E. urophylla Blake, com quatro meses de idade, obtidas do plantio de mudas por estaquia em vasos de $3 \mathrm{~kg}$ de capacidade. $\mathrm{O}$ substrato dos vasos constituiu de mistura de solo:areia:esterco, proporção 3:1:1. Inocularam-se, com micélio do isolado RH-3, brotações com cerca de $50 \mathrm{~cm}$ de altura, aos 60 dias após decepa. Para simular inoculação natural, aplicou-se sobre o solo, ao redor da base das plantas, $20 \mathrm{ml}$ de suspensão micelial a $0,5 \mathrm{~g} / \mathrm{l}$ (Silveira et al., 2000). Inocularam-se três plantas por tratamento fungicida. Após inoculadas, as plantas foram mantidas em câmara de nevoeiro ( 15 min ligada e 45 min desligada), a $25 \pm 2$ ${ }^{\circ} \mathrm{C}$, fotoperíodo de $12 \mathrm{~h}$ (lâmpadas brancas e frias), por quatro dias, para induzir crescimento micelial ascendente. Pulverizouse, em média, $50 \mathrm{ml}$ de calda fungicida por planta. Após secagem, as plantas pulverizadas foram retornadas e mantidas em câmara de nevoeiro, nas mesmas condições, por mais cinco dias, quando se avaliou a incidência de folhas com lesões. Compararam-se os fungicidas pencycuron ( $2 \mathrm{~g} / \mathrm{l})$, methyltolclophos (1,5 g/l), iprodione (1,5 g/l), benomyl ( $1 \mathrm{~g} / \mathrm{l})$, captan $(2 \mathrm{~g} / \mathrm{l})$ e thiram $(2,1 \mathrm{~g} / \mathrm{l})$. Para todos os tratamentos, incluindo a testemunha, adicionou-se espalhante adesivo (alquil-fenolpoliglicoléter) $0,03 \%$ (v/v) à calda de pulverização.

\section{Pulverização com fungicidas no jardim clonal, para controle da queima de folhas e da mela de estacas de eucalipto}

O experimento foi conduzido em duas fases, inicialmente em jardim clonal e, posteriormente, na casa de vegetação e aclimatação.

Jardim clonal - O experimento foi realizado em área plantada com um só clone, localizada próxima ao viveiro da Cenibra Florestal S/A, em Belo Oriente, MG, de junho a setembro de 1995. O delineamento experimental utilizado foi o de blocos ao acaso, em esquema fatorial $7 \times 3$ (sete tratamentos fungicidas $\mathrm{x}$ três datas de coleta e estaquia), com quatro repetições. A parcela experimental constituiu-se de 30 cepas (tocos de árvores pósabate), distribuídas em cinco fileiras de seis cepas cada (espaçamento $0,9 \times 0,4 \mathrm{~m}$ ) e, como parcela útil, consideraram-se as 12 plantas centrais. Todos os blocos e tratamentos foram dispostos linearmente ao longo destas cinco fileiras.

Antes da primeira pulverização, fez-se rigorosa poda de limpeza nas cepas, das quais se removeram todos os ramos e folhas doentes ou contendo micélio e escleródios do patógeno. Nessa operação, foi avaliado o número de ramos removidos (doentes) e remanescentes (sadios), em cada parcela. Quando todos os ramos de uma cepa estavam doentes, foram deixados, no mínimo, dois ramos, para garantir a sobrevivência da cepa. Para análise dos dados, os dois ramos remanescentes foram considerados como se tivessem sido removidos. Nos blocos 1 e 3, os resíduos da poda de limpeza foram deixados entre as fileiras de mesma parcela, afastados das cepas, e, nos blocos 2 e 4, os resíduos foram removidos da área.

Os tratamentos, selecionados com base nos ensaios anteriores, consistiram de pulverizações semanais com: (1) benomyl a 0,5 g/l, (2) methyl-tolclophos a $1 \mathrm{~g} / \mathrm{l}$, , (3) pencycuron a $1 \mathrm{~g} / \mathrm{l}$, (4) iprodione a $1 \mathrm{~g} / \mathrm{l}$, (5) captan a $1 \mathrm{~g} / \mathrm{l}$, (6) mistura de captan a $1 \mathrm{~g} / \mathrm{l}$ com benomyl a $0,5 \mathrm{~g} / \mathrm{l}$, alternada, semanalmente, com mistura de thiram a $1 \mathrm{~g} / \mathrm{l}$ com benomyl a $0,5 \mathrm{~g} / \mathrm{l}$, (7) água + espalhante adesivo (nonifenol-etoxilado) a $0,1 \%$ (testemunha). Nas pulverizações, a alto volume (1.000 l/ha, pulverizador costal manual), buscou-se proteger a folhagem e, principalmente, atingir os ramos basais e centrais da cepa, visando-se eliminar inóculo na posição onde se formam os brotos novos.

Realizaram-se cinco pulverizações a intervalos semanais, sendo a primeira na data da primeira poda (tempo 0 ). Outras três podas de limpeza foram efetuadas, conjuntamente a outras três avaliações no jardim clonal, após sete, 14 e 28 dias do tempo 0. Nas avaliações, anotou-se o número de ramos removidos (doentes) e o de ramos remanescentes (sadios). $\mathrm{O}$ manejo da irrigação seguiu rotina da empresa (18 $\mathrm{mm}$ a cada três dias, por meio de aspersão por canhão de alto volume). Após cada poda e avaliação, foram efetuadas pulverizações, sendo a última aos 35 dias da data da primeira poda.

Nas avaliações de campo, aos sete e 28 dias, foram coletados da superfície do solo dos blocos 1 e 3 segmentos de ramos contendo escleródios. Os ramos foram acondicionados em sacos de papel e armazenados a $15{ }^{\circ} \mathrm{C}$, para avaliação posterior da viabilidade de escleródios (percentagem de germinação em meio de ágar-água). De cada amostra, selecionaramse três fragmentos de ramos, os quais foram desinfestados parcialmente em solução de hipoclorito de sódio, a 3\% (750 ppm de $\mathrm{Cl}_{2}$ ), por $30 \mathrm{~s}$, lavados em água esterilizada e enxutos sobre papel-toalha. De cada fragmento, transferiram-se, sob microscópio estereoscópio, 12 ou mais escleródios para meio de ágar-água (2\%). Avaliou-se a percentagem de escleródios germinados até os sete dias de incubação a $25^{\circ} \mathrm{C}$, no escuro.

Casa de vegetação e aclimatação - Brotações originárias das parcelas tratadas no jardim clonal foram utilizadas para se avaliar o efeito das pulverizações no enraizamento das estacas e na incidência da mela, na casa de vegetação. Coletaram-se brotações para estaquia aos 15, 32 e 43 dias do tempo 0 (data da primeira poda no jardim clonal). No galpão de estaquia, confeccionaram-se estacas de 6 a $10 \mathrm{~cm}$ de comprimento e com um par de folhas cortadas ao meio. Avaliou-se o número de estacas coletadas por parcela. Não se realizaram quaisquer tratamentos para desinfettar brotações e/ou estacas. Para induzir raízes adventícias, as estacas tiveram suas bases tratadas em hormônio (AIB a 6.000 ppm veiculado em talco) e foram plantadas em substrato $(60 \%$ de vermiculita e $40 \%$ de casca de arroz carbonizada), em tubetes cônicos de $12 \mathrm{~cm}^{3} \mathrm{de}$ capacidade. Utilizaram-se, como suporte das mudas, bandejas 
de plástico de 176 tubetes.

Do galpão, as bandejas com as estacas foram transferidas para canteiros suspensos na casa de vegetação (50\% de luz), com irrigação diurna intermitente. A irrigação, por um sistema de aspersão de alta pressão, foi controlada manualmente, de modo a se manterem as folhas das estacas molhadas. Do quinto ao vigésimo dia após o plantio, as estacas receberam, a cada três dias, adubo foliar a $0,5 \%$ p/v em água (NPK 9:15:6, ácido bórico e sulfato de zinco, na proporção de $1: 1: 1)$. Nas primeiras duas semanas, a cada três dias, removeramse das bandejas estacas doentes ou apodrecidas, com seus respectivos tubetes, para se evitar contaminação das estacas vizinhas e sadias. Durante as limpezas, anotou-se o número de estacas com mela. Para padronizar e comparar os efeitos dos tratamentos fungicidas sobre a incidência da doença na casa de vegetação, considerou-se o número de estacas doentes até o décimo dia da estaquia. Aos 45 dias, avaliou-se o número de estacas enraizadas e as bandejas com as mudas foram transferidas para a aclimatação. As mudas foram mantidas a pleno sol sobre canteiros suspensos, cerca de $1 \mathrm{~m}$ de altura do solo e irrigadas diurna e diariamente por aspersão. Aos 75 dias da estaquia, avaliou-se o número final de mudas sadias por parcela, para cada data de coleta. Para análise dos dados, as estacas que morreram na casa de vegetação e na aclimatação, por causa do enraizamento deficiente, foram consideradas separadamente e computadas para se determinar possível efeito fitotóxico dos fungicidas sobre o enraizamento (percentagem do número de estacas não enraizadas por causa indeterminada).

Coletaram-se amostras, compostas de cinco subamostras, do substrato de enraizamento utilizado no experimento e da casca de arroz carbonizada, para se detectar a presença de inóculo de $R$. solani e Cylindrocladium spp., por meio de isolamento a partir de iscas biológicas de cubos de batata e folhas de Ricinus comunis L. (Ferreira, 1989).

\section{RESULTADOS}

\section{Inibição in vitro do crescimento micelial por fungicidas}

No primeiro ensaio, todos os fungicidas reduziram significativamente o crescimento micelial do isolado $\mathrm{RH} 3$, quando adicionados ao meio de cultura (Tabela 1). Inibição total do crescimento micelial ocorreu com methyl-tolclophos e pencycuron, a partir de $1 \mathrm{ppm}$, thiabendazol, benomyl e iprodione, a partir de $10 \mathrm{ppm}$, e captan e thiram, a partir de 100 $\mathrm{ppm}$. Triadimenol inibiu o crescimento micelial de RH-3 em $87 \%$ a 1 ppm, mas a 10 ppm e a 100 ppm, observou-se crescimento de hifas, ainda que reduzido. A 100 ppm, clorotalonil, carboxin, PCNB e vinclozolin inibiram o crescimento em 94, 86,5, 94 e $94 \%$, respectivamente. A 1.000 ppm, não se observou crescimento micelial em meio contendo os fungicidas, exceto para PCNB e vinclozolin.

No segundo ensaio, os isolados RH-3, RH-10 e RH-15 foram similares quanto à percentagem de inibição do crescimento micelial (PICM), a concentrações crescentes de methyl-tolclophos, benomyl e pencycuron (dados não apresentados). Maiores variações entre os isolados quanto a
PICM ocorreram para iprodione, nas três menores concentrações. Porém, a 30 ppm, iprodione inibiu em 100\% o crescimento micelial de todos os isolados testados (dados não apresentados). Pelos valores de $\mathrm{EC}_{50}$, não se observaram diferenças marcantes entre os oito isolados quanto à sensibilidade a methyl-tolclophos, com valores de $\mathrm{EC}_{50}$ inferiores a 0,1 ppm, exceto RH-08, para o qual a $\mathrm{EC}_{50}$ foi de 0,8 ppm (Tabela 2). Methyl-tolclophos e pencycuron inibiram totalmente o crescimento micelial de todos os isolados a concentrações inferiores a 1 ppm (Tabela 2).

Pulverização com fungicidas no controle da queima das folhas em brotações de mudas envasadas, sob condições controladas

Após as pulverizações, observou-se progresso reduzido da doença em todos os tratamentos fungicidas, em relação a testemunha. Aos dez dias da inoculação, correspondente ao quinto dia após as pulverizações, houve diferença entre os tratamentos e em relação à testemunha, quanto à incidência de folhas lesionadas (Figura 1). Iprodione, benomyl, thiram e methyl-tolclophos foram os mais eficazes e propiciaram médias de incidência de folhas doentes inferiores a 8,5\%, enquanto na testemunha, a incidência de folhas doentes foi de $73 \%$. Com pencycuron e captan, as médias de incidência de folhas doentes foram de 14 e $19 \%$, respectivamente (Figura 1).

\section{Pulverização com fungicidas no jardim clonal, para controle da queima de folhas e da mela de estacas de eucalipto}

Na primeira avaliação da queima de folhas no jardim clonal, antes de se iniciarem as pulverizações, a maioria das parcelas apresentou $100 \%$ de incidência de plantas com ramos doentes. A incidência de ramos doentes nas parcelas variou de 30 a $79 \%$ (média de $62 \%$ e desvio padrão de $12 \%$ ). Após a poda inicial, a doença praticamente desapareceu da área experimental, mesmo nas parcelas testemunhas, o que impossibilitou a comparação dos tratamentos, com base nas avaliações de incidência de ramos doentes. Aos 28 dias após a poda, a

TABELA 1 - Inibição do crescimento micelial (\%) de Rhizoctonia solani AG1-IB (RH-3), em meio de batata-dextrose-ágar (BDA), contendo fungicidas a diferentes concentrações (médias de três repetições, $\mathrm{CV}=$ $10 \%)$

\begin{tabular}{lcccc}
\hline \hline \multirow{2}{*}{ Fungicida } & \multicolumn{4}{c}{ Concentração (ppm) } \\
\cline { 2 - 5 } & $\mathbf{1}$ & $\mathbf{1 0}$ & $\mathbf{1 0 0}$ & $\mathbf{1 . 0 0 0}$ \\
\hline Methyl-tolclophos & 100 & 100 & 100 & 100 \\
Pencycuron & 100 & 100 & 100 & 100 \\
Iprodione & 56 & 100 & 100 & 100 \\
Thiabendazol & 82 & 100 & 100 & 100 \\
Benomyl & 55 & 100 & 100 & 100 \\
Captan & 41 & 92 & 100 & 100 \\
Thiram & 69 & 96 & 100 & 100 \\
Triadimenol & 86 & 97 & 97 & 100 \\
Clorotalonil & 69 & 83 & 94 & 100 \\
Carboxin & 73 & 74 & 86 & 100 \\
PCNB & 79 & 91 & 94 & 97 \\
Vinclozolin & 57 & 88 & 94 & 97 \\
\hline
\end{tabular}




\section{S.F. Silveira et al.}

TABELA 2 - Valores de concentração de fungicida em meio de BDA que inibe o crescimento micelial em $50 \%\left(\mathrm{EC}_{50}\right)$, obtidos para cada combinação de fungicida e de isolado de Rhizoctonia spp.

\begin{tabular}{|c|c|c|c|c|}
\hline \multirow[t]{2}{*}{ Fungicida } & \multirow{2}{*}{$\begin{array}{c}\text { Isolado de } \\
\text { Rhizoctonia spp. }\end{array}$} & \multirow{2}{*}{$\begin{array}{r}\mathbf{E C 5 0} \\
(\mathrm{ppm})\end{array}$} & \multicolumn{2}{|c|}{$\begin{array}{c}\text { Limites do Intervalo de } \\
\text { Confiança }(=\mathbf{5 \%})\end{array}$} \\
\hline & & & Inferior & Superior \\
\hline \multicolumn{5}{|c|}{ Methyl-tolclophos } \\
\hline & RH-03 & 0,05 & 0,040 & 0,060 \\
\hline & RH-05 & 0,01 & 0,008 & 0,012 \\
\hline & RH-06 & 0,01 & 0,008 & 0,012 \\
\hline & RH-08 & 0,80 & 0,720 & 0,880 \\
\hline & RH-10 & 0,02 & 0,012 & 0,008 \\
\hline & RH-11 & 0,04 & 0,027 & 0,530 \\
\hline & RH-15 & 0,05 & 0,045 & 0,055 \\
\hline & RH-18 & 0,04 & 0,036 & 0,046 \\
\hline \multicolumn{5}{|l|}{ Pencycuron } \\
\hline & RH-03 & 0,02 & 0,010 & 0,030 \\
\hline & RH-05 & 0,02 & 0,011 & 0,029 \\
\hline & RH-06 & 0,19 & 0,160 & 0,220 \\
\hline & RH-08 & 0,22 & 0,160 & 0,280 \\
\hline & RH-10 & 0,25 & 0,210 & 0,290 \\
\hline & RH-11 & 0,22 & 0,180 & 0,260 \\
\hline & RH-15 & 0,02 & 0,018 & 0,022 \\
\hline & RH-18 & 0,05 & 0,040 & 0,060 \\
\hline \multicolumn{5}{|l|}{ Iprodione } \\
\hline & RH-03 & 0,40 & 0,300 & 0,500 \\
\hline & RH-05 & 0,65 & 0,540 & 0,710 \\
\hline & RH-06 & 0,42 & 0,350 & 0,490 \\
\hline & RH-08 & 11,10 & 10,600 & 11,600 \\
\hline & RH-10 & 0,69 & 0,580 & 0,800 \\
\hline & RH-11 & 0,06 & 0,046 & 0,074 \\
\hline & RH-15 & 1,80 & 1,540 & 2,240 \\
\hline & RH-18 & 0,70 & 0,570 & 0,830 \\
\hline \multicolumn{5}{|l|}{ Benomyl } \\
\hline & RH-03 & 0,50 & 0,400 & 0,600 \\
\hline & RH-05 & 2,15 & 1,890 & 2,410 \\
\hline & RH-06 & 3,61 & 2,890 & 4,330 \\
\hline & RH-08 & 1,22 & 1,070 & 1,370 \\
\hline & RH-10 & 3,43 & 3,010 & 3,850 \\
\hline & RH-11 & 2,62 & 2,200 & 3,020 \\
\hline & RH-15 & 0,60 & 0,550 & 0,650 \\
\hline & RH-18 & 0,70 & 0,630 & 0,770 \\
\hline
\end{tabular}

incidência de ramos doentes foi nula em todas as parcelas experimentais. Também, não se detectaram diferenças quanto à incidência de ramos doentes nas parcelas dos blocos 1 e 3 , nas quais se mantiveram os resíduos da poda de limpeza, e nas dos blocos 2 e 4 , nas quais se removeram os resíduos culturais originários da poda.

Aos sete dias da poda inicial, coletaram-se facilmente escleródios nos restos de poda mantidos sobre o solo. Já, aos 28 dias, com a fragmentação e decomposição dos resíduos de poda, não foi possível coletar escleródios para avaliação da sobrevivência. A recuperação de colônias de $R$. solani, a partir do plaqueamento de escleródios, coletados aos sete dias da poda, foi próxima a $100 \%$, em todos os tratamentos, incluindo a testemunha.

O efeito de data de coleta das brotações para estaquia foi altamente significativo para todas as variáveis avaliadas no viveiro. Maiores percentagens de estacas e mudas mortas

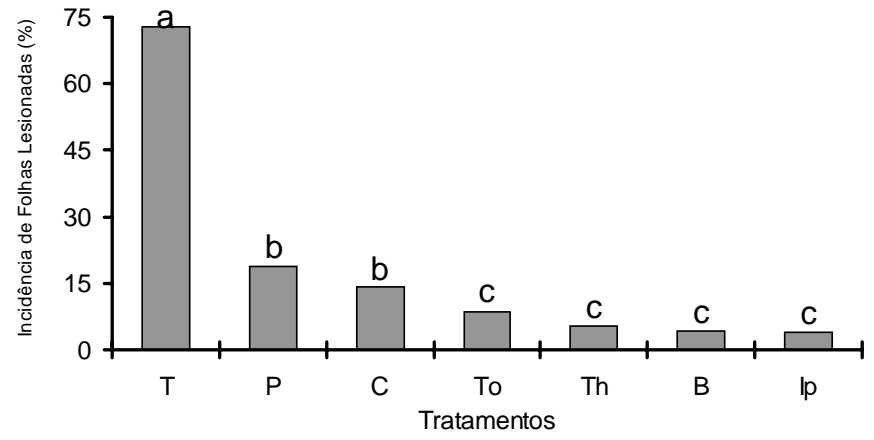

FIG. 1 - Incidência média de folhas de eucalipto (Eucalyptus spp.) lesionadas (\%) por Rhizoctonia solani AG1-IB (isolado RH-3), em brotações de mudas envasadas de eucalipto, aos cinco dias após a pulverização com fungicidas. $\mathrm{T}=$ testemunha, $\mathrm{P}=$ pencycuron a $2 \mathrm{~g} /$ $1, \mathrm{C}=$ captan a $2 \mathrm{~g} / \mathrm{l}, \mathrm{To}=$ methyl-tolclophos a $1,5 \mathrm{~g} / \mathrm{l}, \mathrm{Th}=$ thiram a $2,1 \mathrm{~g} / \mathrm{l}, \mathrm{B}=$ benomyl a $1 \mathrm{~g} / \mathrm{l}, \mathrm{Ip}=$ iprodione a $1,5 \mathrm{~g} / \mathrm{l}$. Médias com mesma letra não diferiram significativamente entre si, a $5 \%$ de probabilidade, pelo teste de Scott-knott. CV $=23 \%$.

por causa indeterminada ocorreram na primeira e na terceira coletas, independentemente dos tratamentos fungicidas (Tabela 3).

Os fungicidas não interferiram no enraizamento de estacas, embora algumas mudas morreram por não enraizar ou por enraizaram deficientemente (Tabela 3). Aos 45 e 75 dias da estaquia, não se obtiveram diferenças significativas entre os tratamentos fungicidas quanto à percentagem de mudas doentes e mortas (que não enraizaram ou que enraizaram deficientemente por causa indeterminada). $\mathrm{O}$ rendimento em estacas/ha, no jardim clonal, pode ter sido influenciado pela pulverização de fungicidas, uma vez que as médias do número de estacas produzidas por cepa diferiram significativamente entre os tratamentos (Tabela 4). Nas parcelas pulverizadas com benomyl e captan, a produção de estacas foi menor que nos demais tratamentos (médias das três datas de coleta de brotos) (Tabela 4).

A percentagem de estacas doentes na casa de vegetação, aos dez dias do estaqueamento, foi dependente da data de coleta e variou entre tratamentos fungicidas (Figura 2). Não houve diferença entre as médias dos tratamentos fungicidas quanto à percentagem de estacas doentes aos dez dias, nas segunda e terceira coletas de brotos. Pulverizações semanais de brotações do jardim clonal com iprodione e com misturas alternadas de benomyl+captan e benomyl+thiram reduziram a incidência da mela de estacas na casa de vegetação, na segunda coleta de brotos (Figura 2). Todavia, o controle não foi satisfatório para ambos os tratamentos, pois a incidência da doença manteve-se acima de $20 \%$.

\section{DISCUSSÃO}

Com base na capacidade em inibir o crescimento micelial de $R$. solani AG1-IB, sete fungicidas (methyl-tolclophos, pencycuron, benomyl, iprodione, thiabendazol, captan e thiram), dentre 12 testados, foram pré-selecionados para o 
TABELA 3 - Número médio de estacas de eucalipto (Eucalyptus spp.) produzidas por cepa, incidência de estacas com mela aos dez dias e incidência de estacas mortas por causa indeterminada, aos 45 e aos 75 dias após a data da estaquia, para cada época de coleta e de estaquia

\begin{tabular}{lcccc}
\hline \hline $\begin{array}{l}\text { Época das coletas } \\
\text { (dias após a poda } \\
\text { no jardim clonal) }\end{array}$ & $\begin{array}{c}\text { Número de } \\
\text { Estacas/cepa }\end{array}$ & $\begin{array}{c}\text { Estacas } \\
\text { doentes aos } \\
\text { dez dias } \\
(\%)^{*}\end{array}$ & $\begin{array}{c}\text { Estacas } \\
\text { mortas aos } \\
\mathbf{4 5} \text { dias } \\
(\%)\end{array}$ & $\begin{array}{c}\text { Estacas } \\
\text { mortas aos } \\
\mathbf{7 5} \text { dias } \\
(\%)\end{array}$ \\
\hline 14 & $5,0 \mathrm{~b}^{* *}$ & $12,4 \mathrm{a}$ & $31,2 \mathrm{a}$ & $51,9 \mathrm{a}$ \\
32 & $8,9 \mathrm{a}$ & $34,8 \quad \mathrm{c}$ & $7,0 \quad \mathrm{~b}$ & $2,2 \quad \mathrm{c}$ \\
43 & $7,9 \mathrm{a}$ & $19,8 \mathrm{~b}$ & $35,1 \mathrm{a}$ & $42,0 \mathrm{~b}$ \\
$\mathrm{CV}(\%)$ & 28 & 23 & 46 & 34 \\
\hline
\end{tabular}

* Efeito dependente do tratamento fungicida.

** Médias com mesma letra, em cada coluna, não diferiram entre si, a $5 \%$ de probabilidade, pelo teste de Scott-knott.

TABELA 4 - Número médio de estacas de eucalipto (Eucalyptus spp.) produzidas por cepa e número estimado de estacas produzidas por hectare no jardim clonal, para cada tratamento fungicida (médias de três épocas de coletas e de quatro repetições)

\begin{tabular}{lcccc}
\hline \hline $\begin{array}{l}\text { Tratamento } \\
\text { Fungicida }\end{array}$ & $\begin{array}{c}\text { Calibração } \\
\text { (kg/ha) }\end{array}$ & $\begin{array}{c}\text { Número de } \\
\text { estacas/cepa }\end{array}$ & $\begin{array}{c}\text { Numero de } \\
\text { estacas/ha } \\
\text { (x 1.000) }\end{array}$ \\
\hline Benomyl & 0,5 & 6,3 & $\mathrm{~b} *$ & 175 \\
Methyl-tolclophos & 1,0 & $7,3 \mathrm{a}$ & 203 \\
Pencycuron & 1,0 & $7,8 \mathrm{a}$ & 217 \\
Iprodione & 1,0 & $7,5 \mathrm{a}$ & 208 \\
Captan & 1,0 & $5,8 \mathrm{~b}$ & 161 \\
$* *$ & $* *$ & $8,5 \mathrm{a}$ & 236 \\
Testemunha & sem fungicida & $7,7 \mathrm{a}$ & 214 \\
\hline
\end{tabular}

* Médias com mesma letra, em cada coluna, não diferiram entre si, a 5\% de probabilidade, pelo teste de Scott-knott. CV $=28 \%$.

** Mistura de captan $1,0+$ benomyl 0,5 alternada com mistura de thiram $1,0+$ benomyl 0,5 .

controle da queima de folhas e da mela de estacas de eucalipto. Methyl-tolclophos, pencycuron, benomyl e iprodione foram ainda testados contra oito isolados de Rhizoctonia spp. Os valores de $\mathrm{EC}_{50}$ variaram com a combinação fungicida/isolado, mas não se observou caso algum de insensibilidade aos quatro últimos fungicidas testados. Resultados similares, para benomyl e iprodione, foram obtidos com sete isolados de $R$. solani (AG1 a AG4) e sete isolados binucleados de Rhizoctonia sp. (Martin et al., 1984). Isolados pertencentes a dez grupos de anastomose de $R$. solani (AG1 a AG10), bem como pertencentes a Rhizoctonia spp. binucleadas, foram igualmente sensíveis a baixas concentrações de methyl-tolclophos, com valores de $\mathrm{EC}_{90}$ inferiores a 3 ppm (Kataria et al., 1991a, 1991b). Todavia, para $R$. solani AG1, os autores observaram ampla variação nos valores de $\mathrm{EC}_{90}$ a pencycuron (1 a $500 \mathrm{ppm}$ ), alto valor de $\mathrm{EC}_{90}$ para benomyl $(38 \mathrm{ppm})$ e baixo valor de $\mathrm{EC}_{90}$ para iprodione (1,8 ppm). Segundo Kataria et al. (1991a), a eficiência de methyl-tolclophos e iprodione para isolados pertencentes a grupos de anastomose distintos de $R$. solani e, no caso de methyl-tolclophos, também para espécies binucleadas de

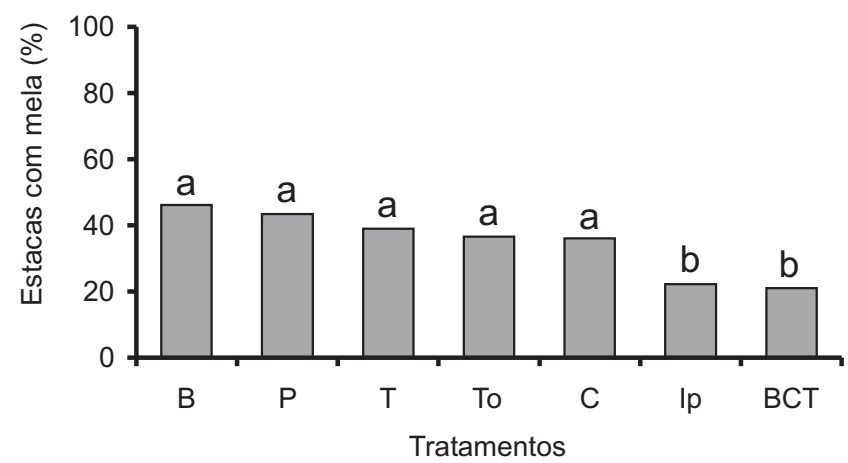

FIG. 2 - Incidência média de estacas de eucalipto (Eucalyptus spp.) com mela (\%), aos dez dias da data de estaquia, na segunda coleta feita ao $32^{\circ}$ dia da poda, após pulverizações de fungicidas nas brotações do jardim clonal. $\mathrm{B}=$ benomyl $(0,5 \mathrm{~kg} / \mathrm{ha})$, To = methyl-tolclophos $(1$ $\mathrm{kg} / \mathrm{ha}), \mathrm{P}=$ pencycuron $(1 \mathrm{~kg} / \mathrm{ha}), \mathrm{Ip}=$ iprodione $(1 \mathrm{~kg} / \mathrm{ha}), \mathrm{C}=$ captan $(1 \mathrm{~kg} / \mathrm{ha}), \mathrm{BCT}=$ mistura de benomyl $(0,5 \mathrm{~kg} / \mathrm{ha})+\operatorname{captan}(1$ $\mathrm{kg} / \mathrm{ha})$ alternada com mistura de benomyl $(0,5 \mathrm{~kg} / \mathrm{ha})+$ thiram $(1 \mathrm{~kg} /$ ha) e $\mathrm{T}=$ testemunha. Médias com mesma letra não diferiram estatisticamente entre si, pelo teste de Scott-knott, a 5\% de probabilidade. $\mathrm{CV}=23 \%$.

Rhizoctonia spp., pode ser explicado pelo fato de esses fungicidas possuírem múltiplos sítios de ação nas células fúngicas. Iprodione induz peroxidação de lipídios, desarranjo de membranas das mitocôndrias e do retículo endoplasmático e reprime vias metabólicas diversas (Lyr, 1987, citado por Kataria et al., 1991a). Methyl-tolclophos, por sua vez, pode inibir a citocinese e causar colapso celular (Kato, 1983; citado por Kataria et al., 1991a) e, como um organofosforado, pode interferir na síntese da fosfatidilcolina (Kodama \& Akatsuka, 1983, citados por Kataria et al., 1991a). A sensibilidade variável de Rhizoctonia spp. a pencycuron e a benomyl, pode ser explicada pelo fato de esses fungicidas terem modo de ação sítio-específica (Kataria et al., 1991a; 1991b). A sensibilidade de $R$. solani e Rhizoctonia spp. à pencycuron é altamente variável, mesmo entre isolados de mesmo grupo de anastomose (Roberts \& Stephens, 1984; Sumner, 1987). Segundo Ueyama et al. (1993), pencycuron é a única molécula ativa do fungicida na célula. A ativação metabólica e a detoxicação não explicam as variações de sensibilidade entre isolados, as quais poderiam ser decorrentes de diferenças de permeabilidade da membrana celular ou de afinidade do princípio ativo ao sítio-alvo.

Sob condições controladas, pulverização com fungicidas pré-selecionados no ensaio in vitro protegeram brotações de mudas envasadas da colonização por $R$. solani AG1 (isolado RH-3). Com iprodione, benomyl, methyltolclophos e thiram $(2,1 \mathrm{~g} / \mathrm{l})$, obtiveram-se, respectivamente, médias de 4,0, 4,4, 5,2 e 8,4\% de incidência de folhas lesionadas, enquanto na testemunha esta foi de $73 \%$. Captan e pencycuron foram menos efetivos em impedir a colonização das brotações pelo patógeno, com médias de incidência de folhas lesionadas de 14 e $19 \%$, respectivamente.

Em jardim clonal, sob condições de inoculação natural, avaliou-se a eficiência de pulverizações de brotações com 


\section{S.F. Silveira et al.}

fungicidas, associadas à poda de limpeza e à coleta seletiva e contínua de brotos, para o controle da queima de folhas e da mela de estacas de eucalipto. Considerando-se a alta intensidade inicial da doença na área experimental, os fungicidas não poderiam ser empregados, sem a poda de limpeza. Após a poda, entretanto, não se observou progresso da doença no campo. As epidemias de queima de folhas em brotações de eucalipto no campo são esporádicas, de curta duração e altamente dependentes das condições ambientais, de temperatura e de umidade. $\mathrm{O}$ experimento pode ter sido instalado após as condições ambientais não estarem mais favoráveis à doença no campo. Por outro lado, o efeito da poda pode ter suplantado o efeito da pulverização com fungicidas no controle da doença, ao eliminar o inóculo das cepas e ao alterar as condições microclimáticas, resultando em maior ventilação e maior insolação nas cepas. Mesmo assim, quando brotações tratadas e aparentemente sadias foram utilizadas para estaquia, não houve redução satisfatória na incidência da mela de estacas na casa de vegetação, para todos os fungicidas. Outras fontes de inóculo foram descartadas, pois os tubetes e as bandejas utilizados foram novos e não se conseguiu isolar o patógeno do substrato. Observou-se, contudo, redução significativa no número de estacas produzidas/cepa, quando se pulverizaram as brotações com captan ou benomyl. Tais diferenças poderiam ser atribuídas a fitotoxicidade, uma vez que não se observou progresso da doença após a poda e remoção dos ramos doentes. Todavia, não se observaram quaisquer sintomas de fitotoxicidade nas brotações pulverizadas e nenhum tratamento fungicida reduziu significativamente o enraizamento das estacas. Atribuíram-se as diferenças no rendimento de estacas a variações quanto ao vigor das cepas na área experimental. Aparentemente, os fungicidas iprodione, benomyl, captan, thiram, methyl-tolclophos e pencycuron, nas dosagens recomendadas, podem ser pulverizados em brotações de eucalipto, sem riscos de danos diretos a essas ou as mudas produzidas por enraizamento de estacas.

Esperava-se que a incidência da mela das estacas na casa de vegetação fosse reduzida gradativamente com as pulverizações de fungicidas e com as podas sucessivas no jardim clonal. Esperar-se-iam assim, maiores diferenças entre os tratamentos fungicidas e a testemunha na primeira coleta de brotos. Todavia, a percentagem de mudas sadias, aos 45 e aos 75 dias da estaquia, foi menor na segunda coleta de brotos, assim como foi alta a incidência da mela de estacas. Os maiores percentuais de mudas mortas por causa indeterminada ocorreram na primeira e terceira coletas, em função do enraizamento deficiente, provavelmente, pelas más condições fisiológicas das brotações. A poda inicial foi rigorosa e, provavelmente, enfraqueceu as cepas, de modo que as primeiras brotações, coletadas após 15 dias da poda drástica, encontravam-se fisiologicamente debilitadas. O intervalo de 17 dias, além dos 15 dias iniciais, entre a primeira e a segunda coleta de brotos, pode ter sido mais adequado, pois propiciou a produção de estacas com maior capacidade de enraizamento. O intervalo de 11 dias, entre a segunda e a terceira coletas, pode ter sido insuficiente para produzir estacas aptas a enraizar, na época do experimento.

$\mathrm{Na}$ segunda coleta de brotos, pulverizações de brotações com iprodione ou com misturas alternadas de benomyl + captan e benomyl + thiram reduziram significativamente a incidência da mela de estacas na casa de vegetação, apesar de o controle da doença não ter sido satisfatório. Possivelmente, quando se iniciaram as pulverizações no jardim clonal, boa parte das novas brotações já haviam sido contaminadas pelo crescimento micelial epifítico do patógeno. Conseqüentemente, grande parte das estacas obtidas já se encontrava infettada, o que explicaria a baixa eficiência de controle na casa de vegetação. Como observado nos ensaios in vitro, os fungicidas tiveram efeito fungistático sobre o inóculo de Rhizoctonia spp., mas foram pouco eficientes como erradicantes de micélio e escleródios do fungo (Silveira et al, 1992a; 1992b).

Pulverizações preventivas em jardim clonal de eucalipto, fora das épocas de ocorrência da queima de folhas, não são recomendadas. A poda de limpeza e as pulverizações devem ser feitas tão logo se constate o início da epidemia, visando minimizar a colonização das brotações pelo patógeno. Para isso, há necessidade de se efetuar o monitoramento da doença no jardim clonal. A antecipação da poda de limpeza permite eliminar menor número de ramos, evitando-se, assim, a debilitação fisiológica das cepas. As pulverizações, dirigidas principalmente às porções centrais e basais das cepas, deverão ser efetuadas logo após a poda de limpeza, de modo a proteger as brotações novas. Recomendam-se pulverizações, a intervalos semanais, de mistura de benomyl+captan, alternada com benomyl+thiram ou iprodione.

Observou-se alta viabilidade de escleródios coletados dos resíduos de poda, mantidos sobre o solo do jardim clonal, após sete dias da poda e pulverização com fungicidas. De Alonso (1997) também constatou alta sobrevivência de micélio e escleródios de $R$. solani AG1-IC, por no mínimo um ano, em restos culturais mantidos na superfície do solo. Recomendase, portanto, juntamente à poda, efetuar a limpeza fitossanitária, durante e logo após a ocorrência de epidemias no jardim clonal. A limpeza consiste da remoção e queima dos ramos contaminados da área. Para permitir a reciclagem de nutrientes, manter a umidade, garantir as características físico-químicas do solo bem como reduzir inóculos de fitopatógenos, recomenda-se o uso de cobertura morta ou aplicação de composto orgânico (Zauza et al., 2001a, 2001b).

\section{AGRADECIMENTOS}

Às agências Conselho Nacional de Desenvolvimento Científico e Tecnológico (CNPq), Coordenação de Aperfeiçoamento de Pessoal de Nível Superior (CAPES) e Fundação de Amparo à Pesquisa do Estado de Minas Gerais (FAPEMIG), pelas bolsas de estudo concedidas ao primeiro autor. A Cenibra - Celulose Nipo-Brasileira S/A, pelo apoio logístico e recursos humanos disponibilizados para execução de experimentos em viveiro da empresa. 
Controle químico da queima de folhas e da mela...

\section{REFERÊNCIAS BIBLIOGRÁFICAS}

ALFENAS, A.C., DEMUNER, N.L. \& SILVA, A.R. Resistência de Cylindrocladium scoparium, agente etiológico de podridão de estacas de Eucalyptus a benomyl. Fitopatologia Brasileira 12:158. 1987. (Resumo).

DE ALONSO, S.K. Trichoderma longibrachiatum e Trichoderma inhamatum como agentes de controle da mela de estacas de eucalipto, causada por Rhizoctonia. (Tese de Doutorado) Viçosa, 1996.

DEMUNER, N.L., FERREIRA, F.A., ALFENAS, A.C. \& REZENDE, D.V. Análise técnica da prática de imersão da base de estacas em suspensão de benomyl para prevenção do apodrecimento de estacas de eucalipto para enraizamento. Fitopatologia Brasileira 13:127. 1988. (Resumo).

EUCLIDES, R.F. Sistema para análises estatísticas e genéticas (SAEG). Divisão de pesquisa e desenvolvimento/CPD, UFV, Viçosa, 1983.

FERREIRA, F.A. Patologia Florestal: principais doenças florestais no Brasil. Viçosa, Sociedade de Investigações Florestais, 1989.

FERREIRA, F.A., DEMUNER, N.L., ALFENAS, A.C. \& DEMUNER, A.J. Análise do tratamento de estacas de eucalipto para enraizamento com benomyl e bioensaios para erradicação de esporos e outras estruturas fúngicas em BDA. Fitopatologia Brasileira 17:9298. 1992.

KATARIA, H.R., HUGELSHOFER, U. \& GISI, U. Sensitivity of Rhizoctonia species to different fungicides. Plant Pathology 40:203211. 1991a.

KATARIA, H.R., VERMA, P.R. \& GISI, U. Variability in the sensitivity of Rhizoctonia solani anastomosis groups to fungicides. Agriculture Canadian Research Station, Sakatoon, 1991b.

MARTIN, S. B., LUCAS, L. T. \& CAMPBELL, C. L. Comparative sensitivity of Rhizoctonia solani and Rhizoctonia-like fungi to selected fungicides in vitro. Phytopathology 74:778-781. 1984.

REZENDE, D.V. \& FERREIRA, F.A. Epifitismo de linhagens de Rhizoctonia solani na doença queima de folhas do eucalipto. Fitopatologia Brasileira 17:204. 1992. (Resumo).

ROBERTS, D. L. \& STEPHENS, C. T. Sensitivity of Rhizoctonia solani to experimental fungicide NTN 19701. Phytopathology 74:854.
1984. (Resumo).

SILVEIRA, S.F. \& ALFENAS, A.C. Caracterização de isolados de Rhizoctonia spp. patogênicos a Eucalyptus por análise de proteínas e isoenzimas. Fitopatologia Brasileira 25:125-130. 2001.

SILVEIRA, S.F., ALFENAS, A.C., CAMPINHOS, C.N. \& RODRIGUES, L.A. Influência da pulverização de fungicidas sobre o enraizamento e a brotação de estacas de eucalipto. Fitopatologia Brasileira 18:308. 1993. (Resumo).

SILVEIRA, S.F., ALFENAS, A.C., FERREIRA, F.A. \& SUTTON, J.C. Characterization of Rhizoctonia species associated with foliar necrosis and leaf scorch of clonally-propagated Eucalyptus in Brazil. European Journal of Plant Pathology 106:27-36. 2000.

SILVEIRA, S.F., ALFENAS, A.C., FERREIRA, F.A. \& WADT, L.H.O. Eficiência de produtos químicos para erradicação de inóculo de Cylindrocladium e Rhizoctonia em estacas de eucalipto para enraizamento. Fitopatologia Brasileira 17:174. 1992a. (Resumo).

SILVEIRA, S.F., FERREIRA, F.A. \& ALFENAS, A.C. Eficiência de produtos químicos para a erradicação de escleródios de Rhizoctonia solani em estacas de eucalipto. Fitopatologia Brasileira 17:223. 1992b. (Resumo).

SUMNER, D. R. Efficacy of pencycuron against isolates representing different anastomosis groups of Rhizoctonia solani and Rhizoctonialike binucleate fungi. Plant Disease 71:515-518. 1987.

UEYAMA, I., ARAKI, Y., KUROGOCHI, S. \& YAMAGUCHI, I. Metabolism of the phenylurea fungicide, pencycuron, in sensitive and tolerant strains of Rhizoctonia solani. Journal of Pesticide Science 18:109-117. 1993.

ZAUZA, E.A.V, ALFENAS, A.C., MAFFIA, L.A., SILVEIRA, S.F. \& FERNANDES, D. Flutuação de inóculo de Rhizoctonia spp. e Cylindrocladium spp. em jardim clonal de Eucalyptus grandis, sob diferentes tipos de cobertura morta. Summa Phytopathologica 27:245250. 2001a.

ZAUZA, E.A.V., ALFENAS, A.C., MAFFIA, L.A., SILVEIRA, S.F., FERNANDES, D. \& LEITE, F.P. Manutenção de umidade e temperatura do solo em jardim clonal de Eucalyptus e aumento do índice de enraizamento de estacas, sob diferentes tipos de cobertura morta. Revista Árvore 25:289-293, $2001 \mathrm{~b}$. 